\title{
An approach based on diffusion to study ligand-macromolecule interaction $^{*}$
}

\author{
Mohammad R. Housaindokht ${ }^{1 凶}$, Mahmood Bahrololoom ${ }^{1}$, Shirin Tarighatpoor ${ }^{1}$ \\ and Ali A. Mossavi-Movahedi ${ }^{2}$ \\ ${ }^{1}$ Biochemistry Laboratory, Department of Chemistry, Faculty of Science, Ferdowsi University of \\ Mashhad, Iran; ${ }^{2}$ institute of Biochemistry and Biophysics, University of Teheran, Iran
}

Received: 02 January, 2002, revised: 17 April, 2002; accepted: 22 May, 2002

Key words: binding isotherm, hen egg-white lysozyme, ligand-protein interaction, methyl orange

\begin{abstract}
A new approach has been developed to study binding of a ligand to a macromolecule based on the diffusion process. In terms of the Fick's first law, the concentration of free ligand in the presence of a protein can be determined by the measurement of those ligands which are diffused out. This method is applied to the study of binding of methyl-orange to lysozyme in phosphate buffer of $\mathrm{pH} 6.2$, at $30^{\circ} \mathrm{C}$. The binding isotherm was determined initially, followed by application of the Hill equation to the data obtained, then binding constant and binding capacity were estimated.
\end{abstract}

Ligand binding to macromolecules is one of the most interesting fields of research these days. Different methods such as equilibrum dialysis (Jones \& Brass, 1990), spectroscopy (Kurachi et al., 1995), ultrafiltration (Maria \& Antonella, 1992), and gel chromatography (Cann \& Hinman, 1976; Andreu, 1985) have been used to this purpose.

In vivo, ligand binding generally accompanies other processes, which also affect the concentration of the ligand (Gram, 1990). For example, when a drug is injected into a vein the blood proteins in the area bind to the max- imum amount of the drug, i.e. ligand. However, due to blood flow and the process of drug absorption, the concentration of the drug is gradually reduced, thus ligand binding is affected and reversed.

This paper introduces an approached based on diffusion which besides its simplicity compared to other approaches, is to some extent similar to the in vivo situation. Due to the short span of time needed for the experiment, this approach is suitable to study ligand binding systems in which ligand or macromolecule or both are unstable.

\footnotetext{
Financial assistance from the Research Council of the Ferdowsi University is gratefully acknowledged.

${ }^{凶}$ To whom correspondence should be addressed; fax: 009851843 8032;

e-mail: Mhousaindokht@science1.um.ac.ir
}

Abbreviations: HEWL, hen egg-white lysozyme; MO, methyl orange. 
In this project the binding of methyl orange, an anionic dye, to hen egg-white lysozyme (pI 10.5) in phosphate buffer at $\mathrm{pH} 6.2$ in which it would have a positive charge (Palmer et al., 1948), is investigated. Lysozyme self-association has been reported (Denier \& Wiliams, 1970; Sophianopoulos \& Vanholde, 1961, 1964; Adams \& Filmer, 1966) in solutions with a protein concentration larger than $0.1 \%$ and at $\mathrm{pH} \geq 7$. In the present work lysozyme concentration and $\mathrm{pH}$ were so chosen that the self-association would not occur.

\section{MATERIALS AND METHODS}

Hen egg-white lysozyme (HEWL) and other chemicals of analytical grade, were obtained from Merck Co. Distilled water was used for the preparation of the solutions. The Visking membrane dialysis tubing (relative molecular mass cut-off 10000-14000) was from SIC (Eastleigh, Hampshire, U.K.).

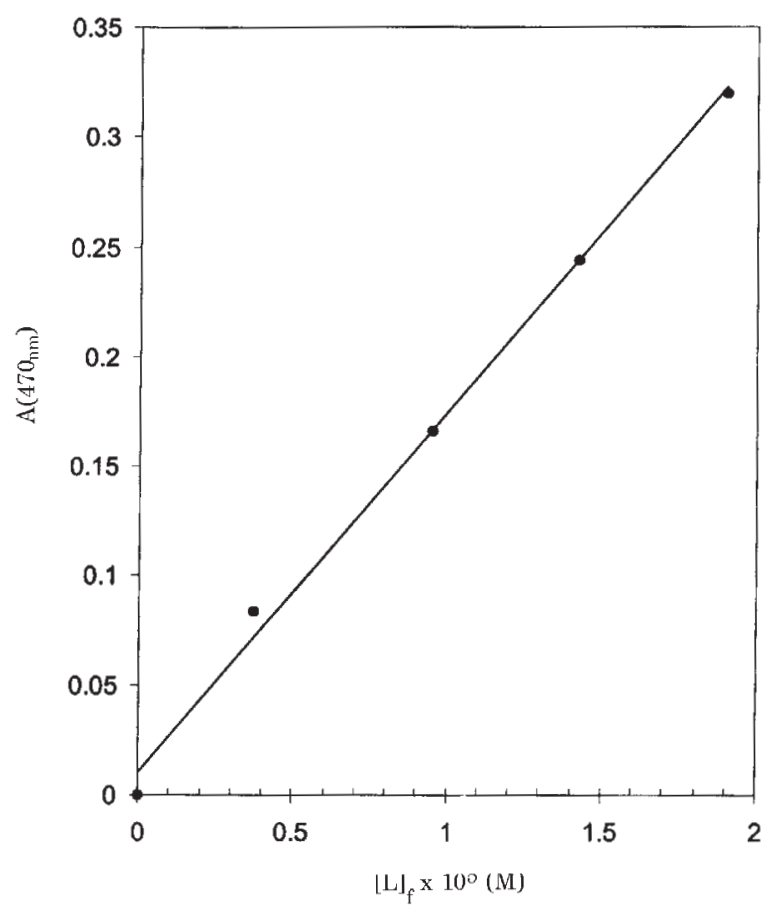

Figure 1. Absorbance of free methyl orange at $470 \mathrm{~nm}$ in $10 \mathrm{mM}$ phosphate buffer, pH 6.2.

$[\mathrm{L}]_{\mathrm{f}}$, concentration of the dye.
The concentration of methyl orange was determined by spectrophotometric method by means of a standard curve. In the first part of the experimental work, $3 \mathrm{ml}$ of $10 \mathrm{mM}$ phosphate buffer solution, $\mathrm{pH} 6.2$, containing methyl orange at $8.25 \times 10^{-4} \mathrm{M}$ was put into a dialysis bag which was placed in $15 \mathrm{ml}$ of buffer solution, in a way that the level of solution inside and outside the bag became nearly identical. The outside solution was stirred regularly and MO concentration therein was measured every $10 \mathrm{~min}$.

In the second part of the experiments which was in fact the main part of the study, $3 \mathrm{ml}$ of the buffer solution containing MO $(8.25 \times$ $10^{-4} \mathrm{M}$, as above $)$ and lysozyme $\left(8.25 \times 10^{-3}\right.$ $\%, \mathrm{w} / \mathrm{v}$ ) was put into a bag. MO concentration outside the dialysis tubing was measured as above.

For the standard curve solutions of MO with concentrations in the range of $0-2 \times 10^{-5} \mathrm{M}$ were prepared in the phosphate buffer and their absorptions were determined at $470 \mathrm{~nm}$. The standard curve is shown in Fig. 1.

\section{RESULTS AND DISCUSSION}

The first Fick's law states that:

$J=-D \frac{d C}{d x}$

where: $J$ is flux, $D$ is the diffusion coefficient and $d C / d x$ is the gradient of concentration.

Given in the experiments the volume of the solutions inside and outside of the bag are actually fixed, finite and stirred, thus:

$\frac{\Delta C}{\Delta x}=\frac{\left(C_{i}-C_{o}\right)}{d}$

and

$J_{i \rightarrow o}=\frac{1}{A} \cdot \frac{d n}{d t}=-D \cdot \frac{C_{i}-C_{o}}{d}$ 
where: $d$ is the constant thickness of the membrane, $n$ is the number of moles of ligand, $C_{i}$ and $C_{O}$ are the concentrations of ligand inside and outside, respectively, and $A$ is a constant. Under the above conditions:

$\frac{d n}{d t} \propto \frac{d C_{i}}{d t} \propto-\frac{d C_{o}}{d t}$

and

$$
\frac{d C_{o}}{d t}=k\left(C_{i}-C_{o}\right)
$$

where $k$ is a constant.

The above equation indicates that the variation of $d C_{O} / d t$ with $\Delta C=C_{i}-C_{o}$ should be linear. The values of $d C_{o} / d t$ can be determined at different times. $C_{i}$ can also be determined in the absence of the protein thus $\Delta C=C_{i}-C_{O}$ is evaluated. ${ }^{1}$

Although the above equation (3) is not linear in practice, it can be used to construct a calibration curve, from which the concentration of the free ligand in the presence of the protein $\left(C_{i}^{\prime}\right)$ can be determined at a known ligand concentration outside the bag, $C_{O}^{\prime}$.

In the absence of the protein, the concentrations of the ligand diffused out, $C_{o}$, are measured at different times and the $C_{O}$ values plotted against $t$, wherefrom the rate $d C_{o} / d t$ values are obtained. By determining corresponding concentrations of the ligand inside the bag, the calibration curve, i.e. a plot of $d C_{o} / d t$ versus $\Delta C=C_{i}-C_{O}$, is obtained.

In the presence of the protein the whole procedure is repeated and the rates $d C_{o}^{\prime} / d t$ determined. Then for the same time intervals the corresponding values of $d C_{o}^{\prime} / d t$ and $C_{o}^{\prime}$ are selected and by the use of the calibration curve ${ }^{2}$ the $\Delta C^{\prime}$ and $C^{\prime}{ }_{i}$ values in the presence of the protein are obtained.

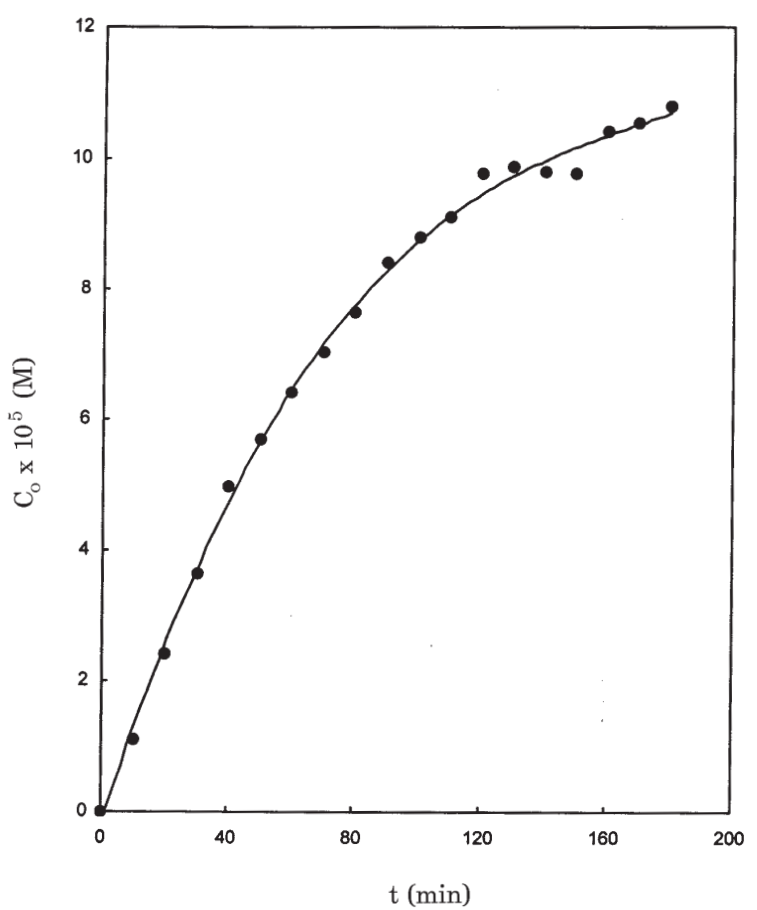

Figure 2. Variation of the concentration of methyl orange outside bag, $C_{o}$, in the absence of lysozyme against time.

The thermodynamic quantities, such as binding constant, $K$, can be estimated by the use of the following equation:

$v=\frac{C_{i}^{o}-C_{i}^{\prime}}{C_{p}}$

where $v$ is the average number ligand bound molecules to the macromolecule. $C_{p}$ and $C_{i}^{o}$ are the total concentration of the protein and initial concentration of the ligand, respectively, and $C_{i}^{\prime}$ was defined earlier.

The method was used to study the binding of MO to HEWL. Figure 2 shows the variation of $C_{o}$ against time in the absence of lysozyme. From this, the values of $d C_{o} / d t$ were evaluated at different times and then fitted to the following equation:

\footnotetext{
${ }_{\text {The adsorption by membrane itself is neglected. }}$

${ }^{2}$ It is obvious that when attaining equilibrium is faster than the rate of diffusion, the calibration curve could be used.
} 


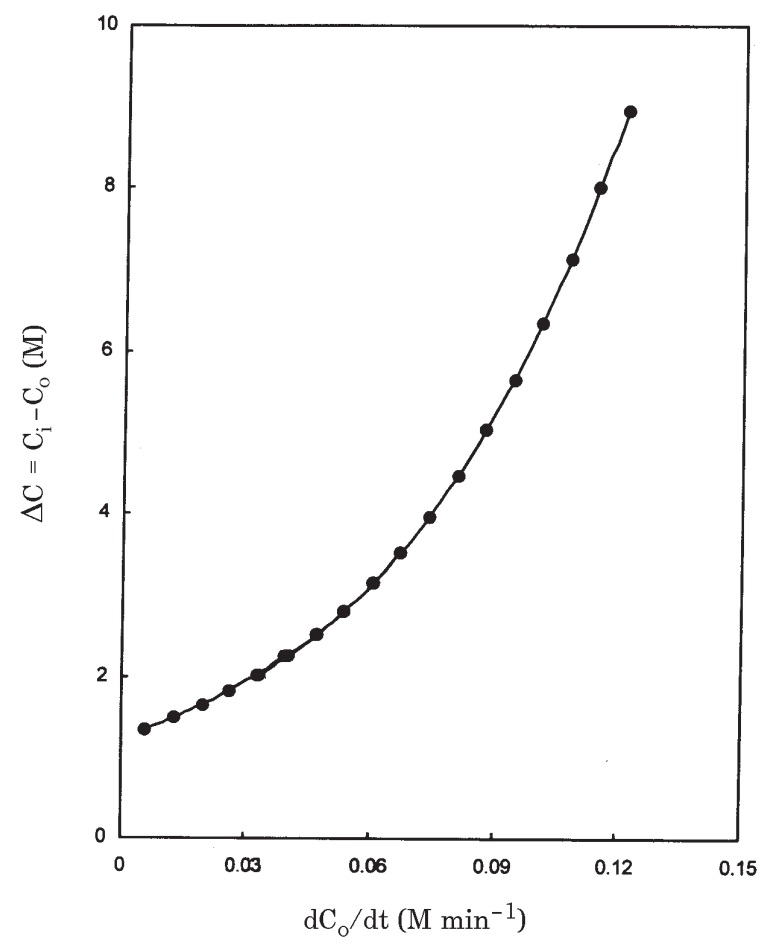

Figure 3. Calibration curve for estimation of $\Delta C=C_{i}-C_{o}$ at corresponding $d C_{o} / d t$ values.

$\frac{d C_{o}}{d t}=0.12149-0.00068 t$

From this equation the values of $d C_{o} / d t$ corresponding to different values of $C_{O}-C_{i}$ at specified times were obtained and hence the calibration curve, that is $C_{i}-C_{o}$ versus $d C_{o} / d t$ was obtained (cf. Fig. 3).

The variation in time of $\mathrm{MO}$ concentration outside the bag, $C_{O}^{\prime}$, in the presence of HEWL is shown in Fig. 4. In this case, again, the values of $d C_{o}^{\prime} / d t$ were fitted to equation:

$\frac{d C_{o}^{\prime}}{d t}=0.10935-0.00055 t$

and then the values of $C_{o}^{\prime}-C_{i}^{\prime}$ corresponding to different values of $d C_{i}^{\prime} / d t$ at specified times were evaluated from the calibration curve, wherefrom the corresponding values of were easily obtained.

The values of $v$ at different concentrations of $C_{i}^{\prime}$ from equation (4) were estimated and then the binding isotherm was plotted (Fig. 5).

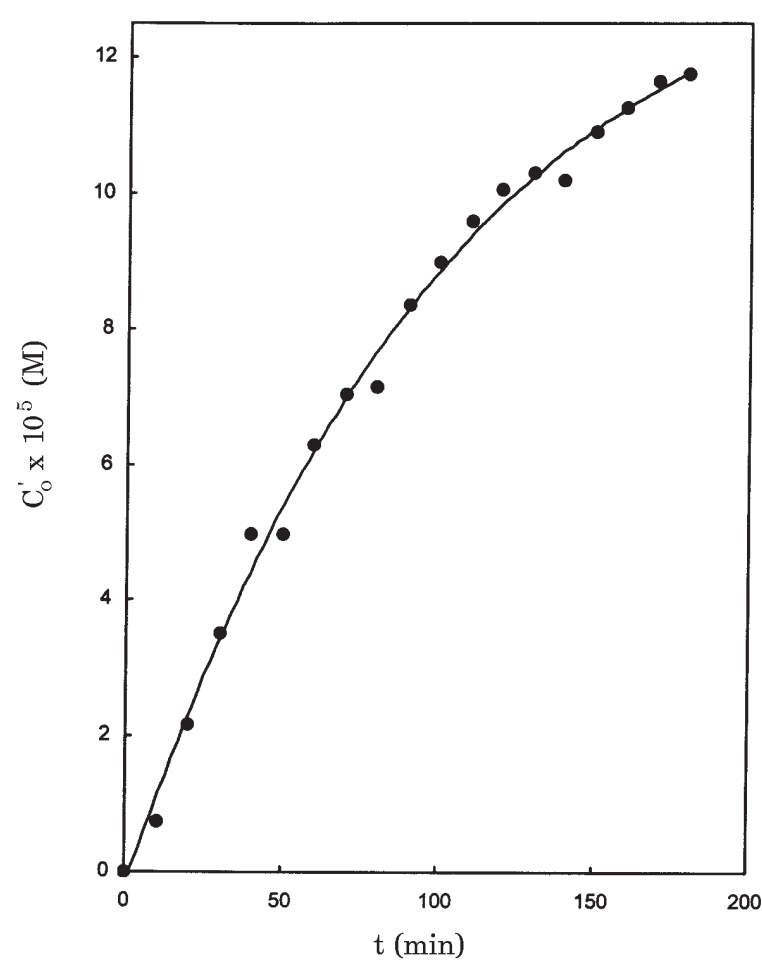

Figure 4. Variation in time of methyl orange concentration, $C_{\boldsymbol{o}}^{\prime}$, outside the bag in the presence of lysozyme.

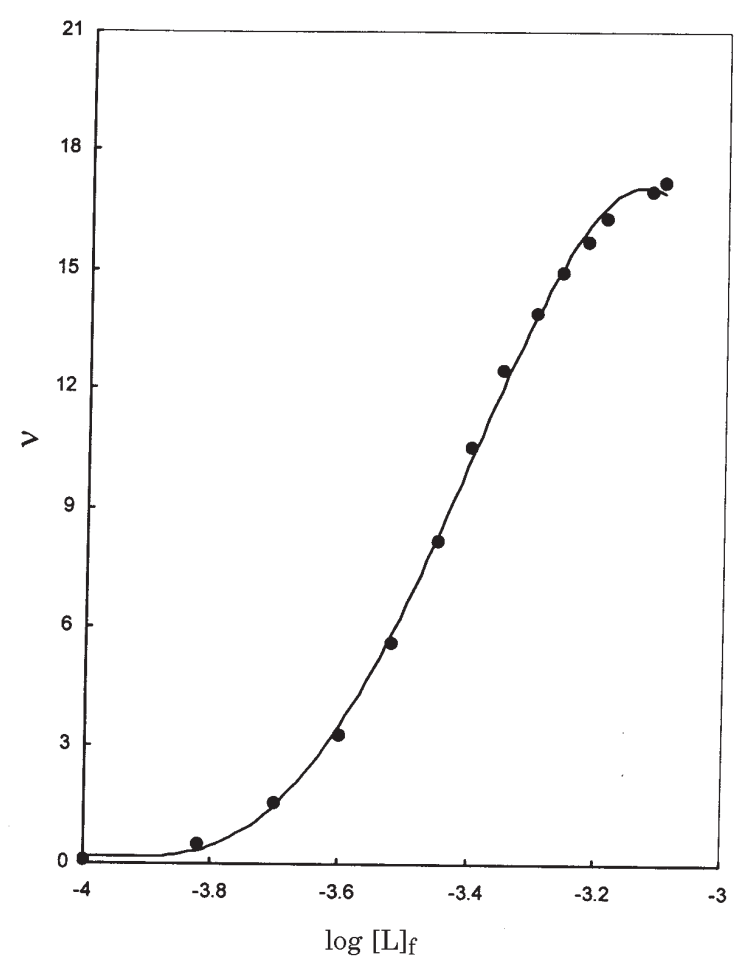

Figure 5. Binding isotherm for methyl orange to lysozyme $8.25 \times 10^{-5} \mathrm{~kg} / \mathrm{dm}^{3}$ at $\mathrm{pH} 6.2$ and $30^{\circ} \mathrm{C}$.

$v$, average number of moles of the ligand bound, $[\mathrm{L}]_{\mathrm{f}}$, concentration of the free ligand. 


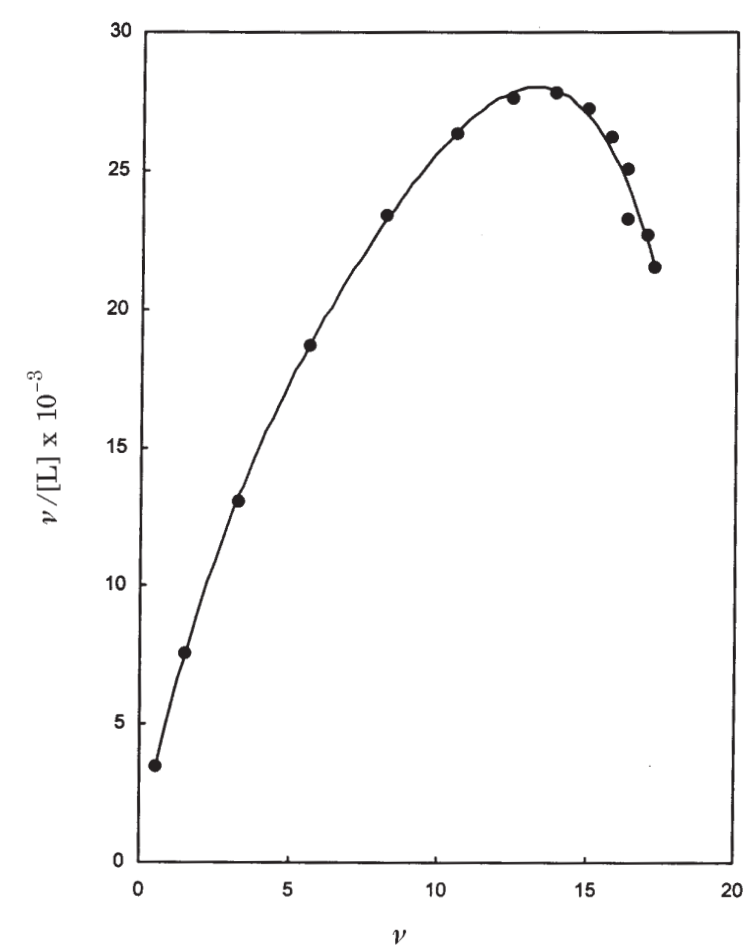

Figure 6. Scatchard plot for methyl orange interaction with lysozyme at $\mathrm{pH} 6.2$, at $30^{\circ} \mathrm{C}$.

The Scatchard plot (Gram, 1990) shown in Fig. 6 is nonlinear which means that the MO-HEWL interaction is positively cooperative. Thus, the Hill equation (Vanholde, 1985):

$\log \left(\frac{v}{g-v}\right)=n_{H} \log K+n_{H} \log [L]$

(where $K$ is the association constant, $n_{H}$ is the Hill coefficient and $[L]$ is the concentration of the free ligand) could be applied and an arbitrary value of $g$ parameter chosen such that it makes the best straight line for Hill plot.

Thus, through this method the values of $g$, $n_{H}$ and $K$ were evaluated to be 18, 3.94 and 2727 , respectively.

It should be mentioned that HEWL at the experimental conditions employed does not have a considerable net positive charge. Hence it is expected that the interaction between MO and HEWL may not be purely electrostatic and may involve also hydrophobic forces. The value of $n_{H}$ confirms this.

\section{R E F E R E N C E S}

Adams ET, Filmer DL. (1966) Sedimentation equilibrium in reacting systems. IV. Verification of the theory. Biochemistry.; 5: 2971-85.

Andreu JM. (1985) Measurment of protein-ligand interaction by gel chromatography. Methods Enzymol.; 117: 346-54.

Aramini JM, Hiroaki T, Ke Y, Nitta K, Hogel J, (1995) Cadmium-113 NMR studies of bovine and human $\alpha$-lactalbumin and equine lysozyme. J Biochem.; 117: 623-7.

Cann JR, Hinman ND. (1976) Hummel-dreyer gel chromatographic procedure as applied to ligand-mediated association. Biochemistry.; 15: $4614-22$.

Denier RC, Wiliamis JW. (1970) Ultracentrifuge; past and present. Biochemistry.; 9: 4260-6.

Gram TE. (1990) Binding of drug to plasma protein. In Modern pharmacology. Raig GR, Stitzel RE. eds, 3rd edn, pp 33-5. Little Brown, Boston.

Jones MN, Brass A. (1990) Interaction between small amphipatic molecules and proteins. In Food polymer, gels and colloids. Dickinson E. ed, pp 65-80. Royal Society of Chemistry, Cambridge.

Maria PG, Antonella R. (1992) Plasma and tissue binding. $J$ Clin Pharmacokinet.; 23: 449-66.

Palmer KJ, Ballantyne M, Calvin JA. (1948) The molecular weight of lysozyme determined by x-ray diffraction method. $J$ Am Chem Soc.; 70: $906-8$.

Sophianopoulos AJ, Vanholde KE. (1961) Evidence for dimerization of lysozyme in alkalin. Solution. J Biol Chem.; 236: pc82-pc3.

Sophianopoulos AJ, Vanholde KE. (1964) Evidence for dimerization of lysozyme in alkaline solution. J Biol Chem.; 239: 2516-24.

Vanholde KE. (1985) Multiple Equilibria. Physical Biochemistry. 2nd edn, pp 63-72. Prentice-Hall. 